
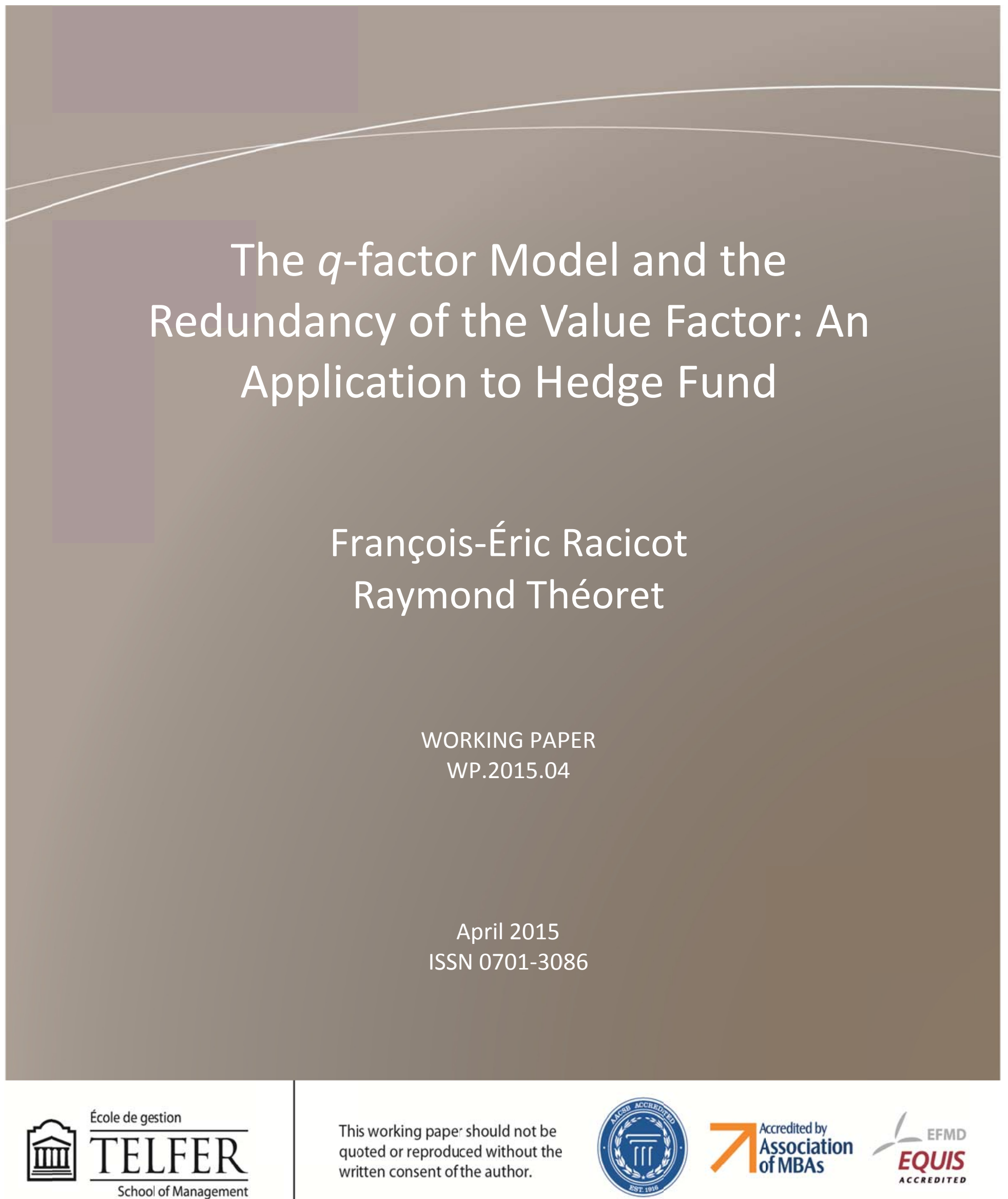


\title{
The $q$-factor model and the redundancy of the value factor: An application to hedge funds ${ }^{\dagger}$
}

\author{
François-Éric Racicot ${ }^{\mathrm{a}, *}$, Raymond Théoret ${ }^{\mathrm{b}}$ \\ a Telfer School of Management, University of Ottawa, 55 Laurier Avenue East, Ottawa, Ontario; CGA-Canada Accounting and Governance \\ Research Center (CGA-AGRC); Chaire d'information financière et organisationnelle, ESG-UQAM; \\ b Université du Québec (Montréal), École des sciences de la gestion, 315 est Ste-Catherine, R-3555, Montréal, Québec; Université du Québec \\ (Outaouais); Chaire d'information financière et organisationnelle, ESG-UQAM.
}

(First draft: April 2015)

\begin{abstract}
We test the new Fama and French five-factor model on a sample of hedge fund strategies. This model embeds the $q$-factor asset pricing model which lies on the $C M A$ and $R M W$ factors. We find that the $H M L$ factor is not redundant for many strategies, as conjectured by Fama and French (2015) in their setting. $H M L$ seems to embed risk dimensions which are not included in the Fama and French new factors. In contrast to Fama and French (2015), the alpha puzzle is robust to the addition of $C M A$ and $R M W$. Furthermore, hedge funds seem to prefer, on the one hand, firms which invest a lot to firms which invest less, and, on the other hand, weak firms over robust ones. Finally, our results are not sensitive to the addition of the Fung and Hsieh (1997, 2001, 2004) seven-factor model. However, the explanatory power of the eleven-factor model is much higher for some hedge fund strategies involved in arbitrage.
\end{abstract}

* Corresponding author. Tel: +1 613-562-5800 (4757).

E-mail addresses: racicot@telfer.uottawa.ca (F.-É. Racicot), raymond.theoret@uqam.ca (R. Théoret).

$\dagger$ Aknowledgements We would like to thank the seminar participants at the SFA Annual Meeting held in November 2012 and 2014. 


\title{
The $q$-factor model and the redundancy of the value factor: An application to hedge funds
}

\begin{abstract}
We test the new Fama and French five-factor model on a sample of hedge fund strategies. This model embeds the $q$-factor asset pricing model which lies on the $C M A$ and $R M W$ factors. We find that the $H M L$ factor is not redundant for many strategies, as conjectured by Fama and French (2015) in their setting. HML seems to embed risk dimensions which are not included in the Fama and French new factors. In contrast to Fama and French (2015), the alpha puzzle is robust to the addition of $C M A$ and $R M W$. Furthermore, hedge funds seem to prefer, on the one hand, firms which invest a lot to firms which invest less, and, on the other hand, weak firms over robust ones. Finally, our results are not sensitive to the addition of the Fung and Hsieh (1997, 2001, 2004) seven-factor model. However, the explanatory power of the elevenfactor model is much higher for some hedge fund strategies involved in arbitrage.
\end{abstract}

Keywords: Hedge fund; $q$-factor model; ICAPM; return smoothing; five-factor model; lookback straddle.

JEL classification: C13; C58; G11; G23.

\section{Le modèle factoriel $q$ et la redondance de HML: Une application aux fonds de couverture}

\section{Résumé}

\begin{abstract}
Nous testons le nouveau modèle à cinq facteurs de Fama et French sur un échantillon de stratégies de fonds de couverture. Ce modèle récupère le modèle factoriel $q$ d'évaluation des actifs qui est basé sur les facteurs $C M A$ et $R M W$. Nous trouvons que le facteur $H M L$ n'est pas redondant pour plusieurs stratégies contrairement à la conjecture de Fama et French (2015) dans leur cadre d'analyse. $H M L$ semble capter les dimensions de risque qui ne sont pas incluses dans les nouveaux facteurs de Fama et French. En contraste avec Fama et French (2015), le puzzle relié à l'alpha est robuste à l'addition de $C M A$ et $R M W$. De plus, les fonds de couverture semblent préférer, d'une part, les firmes qui investissent davantage à celles qui investissent moins, et, d'autre part, les firmes faibles aux firmes robustes. Finalement, nos résultats ne sont pas sensibles à l'addition des sept facteurs du modèle de Fung et Hsieh (1997, 2001, 2004). Cependant, le pouvoir explicatif du modèle à sept facteurs est plus élevé pour quelques stratégies qui sont particulièrement impliquées dans des opérations d'arbitrage.
\end{abstract}

Mots-clefs: Fonds de couverture; modèle factoriel q; ICAPM; lissage du rendement; modèle à 5 facteurs; lookback straddle. JEL classification: C13; C58; G11; G23.

\section{Introduction}

Fama and French (2015) have recently proposed an augmented version of their threefactor asset pricing model. They add two factors to their model: an investment factor and a profitability factor. These factors are associated with the drivers of stocks prices in the $q$-factor asset pricing model or in the investment capital asset pricing model (ICAPM). They are thus well-known in the portfolio theory. For instance, Cochrane (1991) was the first to rely on the $q$ theory to price assets. Hou et al. (2014) have also experimented with a new factor model that consists of a market factor, a size factor, an investment factor and a profitability factor-i.e., return on equity. In complement to these previous articles, Fama and French (2015) study the 
relevance of $C M A^{1}$ and $R M W^{2}$ - respectively the investment and profitability factor-in their original three-factor asset pricing model.

More precisely, Fama and French (2015) intend to study the interactions of CMA and $R M W$ with their original three-factor model. Actually, they find that their value factor $\left(H M L^{s}\right)$ seems to become redundant for describing asset returns in the sense that $R M W$ and especially $C M A$ seem to capture the risk dimensions of $H M L$ : when adding $C M A$ and $R M W$ in their asset pricing model, the factor loading of $H M L$ is no longer significant. Actually, firms whose stocks have a high book-to-market ratio tend to invest less and also to be less profitable. Alternatively, firms whose stocks have a low book-to-market ratio tend to invest aggressively and be profitable (Fama and French, 2015). The factor $H M L$ thus interacts with $C M A$ and $R M W$, this interaction being so high that it would eliminate $H M L$ from the pricing model. However, as mentioned by Fama and French (2015), the redundancy of HML may be attributable to their sample and other studies must be achieved before arriving at this conclusion. According to Fama and French (2015): "This result is so striking we caution the reader that it may be specific to this sample".

In this study, we apply the new Fama and French five-factor model to a sample of hedge fund strategies' returns. We first aim at testing the redundancy of the value factor $(H M L)$ when adding $C M A$ and $H M L$ in the Fama and French three-factor model. In the hedge fund industry, the size factor $(S M B)$ is also very important to explain returns. We must also consider the impact of the two new factors on the loading of $S M B^{t}$ since there are also interactions between size, investment and profitability. Second, we explore whether the introduction of the two new factors attenuates the alpha puzzle observed in the hedge fund industry. As assessed by Fama and French (2015), "if an asset pricing model completely captures expected returns, the intercept is indistinguishable from zero". If the alphas of the hedge fund strategies are reduced in the five-factor model compared to the three-factor one, this will be an indication of the "completeness" of the five-factor model.

Our empirical results show that the $H M L$ factor is quite redundant for most strategies' returns but in several cases, the coefficient of $H M L$ remains significant when adding $C M A$ and $R M W$. The impact of $H M L$ in the three-factor model is shared between $C M A$ and $R M W$. It is difficult to establish that most of the impact of $H M L$ is absorbed by $C M A$, as suggested by Fama

\footnotetext{
${ }^{1} C M A$ is the abbreviation of "conservative minus aggressive" - i.e., a portfolio which is long in stocks of firms with a low ratio of investment to assets and short in stocks of firms with a high ratio of investment to assets.

${ }^{2} R M W$ is the abbreviation of "robust minus weak"-i.e., a portfolio which is long in stocks of robust firms in terms of profitability and short in stocks of weak firms in terms of profitability.

${ }^{3} H M L$ is the abbreviation for "high minus low"-i.e., a portfolio which is long in stocks of firms having a high book-to-market ratio and short in stocks of firms having a low book-to-market ratio.

${ }^{4} S M B$ is the abbreviation for "small minus big"-i.e., a portfolio which is long in stocks of small firms and long in stocks of big firms.
} 
and French (2015). As the coefficient of $H M L$ is usually negative in our regressions, the coefficients of $C M A$ and $R M W$ are also negative. In our sample, hedge funds thus prefer aggressive firms over conservative ones and weak firms over robust ones. Hedge funds are thus in line with the Fama and French's (2015) new puzzle related to portfolios of small stocks whose returns behave like of firms that invest a lot despite low profitability. However, according to the theory of implicit contracts in economics, firms may overinvest to relax their financing constraints $^{5}$ (e.g., Fazarri et al., 1988; Thomas and Worrall, 2014). In this respect, the fivefactor model does not mitigate the hedge funds' alpha puzzle: the alpha is insensitive to the two new factors. As a robustness check, we add to the five-factor model the seven factors proposed by Fung and Hsieh $(1997,2001,2004)$ to price hedge funds' stocks. Our results are essentially unchanged.

This paper is organized as follows. Section 2 discusses the Fama and French five-factor asset pricing model and exposes the methodology used in this study to test the redundancy of $H M L$ in the presence of $C M A$ and $R M W$. In Section 3, we present our data and analyze our empirical results before concluding in Section 4.

\section{The $q$-factor model and the Fama and French five factor model}

The first order condition of the $q$-factor model stipulates that firms will continue to invest until the marginal cost of investment is equal to its marginal benefit or Tobin's $q$ (Tobin, 1969; Hou et al., 2014):

$$
1+a \frac{I_{i t}}{A_{i t}}=E_{t}\left[M_{t+1} \pi_{i t+1}\right]
$$

where $I_{\mathrm{it}}$ is the investment level of firm $i ; A_{i t}$ is the level of firm's assets; $\mathrm{E}_{\mathrm{t}}[\cdot]$ is the expectations operator conditional on the information set available at time $t ; M_{t+1}$ is the discount factor and $\pi_{i t+1}$ is the investment cash-flow. The LHS of (1) is the marginal cost of investment and its RHS, its marginal benefit of investment-i.e., Tobin's $q(1969)$.

Equation (1) may be rewritten as follows:

$$
E\left[r_{i, t+1}\right]=\frac{E_{t}\left(\pi_{i, t+1}\right)}{1+a \frac{I_{i t}}{A_{i t}}}
$$

\footnotetext{
${ }^{5}$ More precisely, firms overinvest when they are in financial distress and expect that projects with positive VAN may rescue them. By doing so, they expropiate their debt stakeholders.
} 
According to equation (2), the stock expected return is related positively to its expected profitability as measured by $E_{t}\left(\pi_{i, t+1}\right)$ and negatively to its investment ratio, as measured by $\frac{I_{i t}}{A_{i t}}$. This is the essence of the $q$-factor model.

The Fama and French (2015) five-factor model adds to its three original factors the profitability and investment factors to capture the teaching of the $q$-factor model. It is formulated as follows:

$$
R_{i t}-r_{f t}=\alpha+\beta_{1}\left[R_{m t}-r_{f t}\right]+\beta_{2} S M B_{t}+\beta_{3} H M L_{t}+\beta_{4} C M A_{t}+\beta_{5} R M W_{t}+\varepsilon_{t}
$$

where $R_{i t}$ is the firm's stock return and $r_{t}$ is the risk-free rate; $R_{m t}$ is the market portfolio return; $S M B$ is a diversified portfolio which is long in small firms' stocks and short in big firms' stocks; $H M L$ is a diversified portfolio which is long in firms whose stocks have a high book-to-market ratio (i.e., value stocks) and which is short in firms whose stocks have a low book-to-market ratio (i.e., growth stocks); $C M A$ is a diversified portfolio which is long in firms embedded with a low investment to assets ratio and short in firms with a high investment to assets ratio. Finally, $R M W$ is a diversified portfolio which is long in firms with high profitability (in terms of net operating revenue to assets or $R O E$ ) and short in firms with low profitability. The addition of the $C M A$ and $R M W$ factors captures the two drivers of expected returns in the $q$-factor model (equation (2)).

The presence of the $S M B$ factor in the return equation may be questionable since it is not a component of the $q$-factor model. But we must understand that the $C M A$ and $R M W$ factors are only proxies for the investment and profitability factors: they are measured with errors. In this context, every factor which helps forecast returns has its place in the asset pricing equation. And since $S M B$ remains a significant factor in the Fama and French's (2015) experiments even after adding $C M A$ and $R M W$ in the Fama and French (2015) experiments, it remains valuable to price assets. In this respect, an empirical asset pricing kernel must span all the states of nature relevant for the estimation of a stock return. If $S M B$ span dimensions of the state space not covered by $C M A$ and $R M W$, it has a role to play in the return equation ${ }^{6}$.

Similarly to the market risk premium and $S M B$, the $C M A$ and $R M W$ factors command a positive premium. In this respect, given firm's profitability, a decrease in $I_{i t}$ in equation (2) leads to an increase in $E\left(r_{i t+1}\right)$. This relationship is well documented in the financial literature (e.g., Hou et al., 2014; Fama and French, 2015). Irving Fisher (1930) has established a negative

\footnotetext{
${ }^{6}$ Note that Fama and French (2015) do not introduce the momentum factor (UMD) proposed by Carhart (1997) and the liquidity factor proposed by Pástor and Stambough (2003) in their new asset pricing model. They justify this omission by the fact that these two factors have regression slopes close to zero in their experiments so they decided to discard them. According to Fama and French (2015), these factors produce trivial changes in model performance.
} 
relationship between return and investment-i.e., the marginal productivity of capital schedule. Moreover, when the cost of capital as measured by $r_{i}$ is high, the level of investment is low because a high cost of capital is associated with a low VAN, all else equal. There are thus many justifications to the negative relationship between expected return and the level of investment. The $C M A$ factor captures this relationship. In other respects, according to equation (2), firms with high profitability provide higher expected returns than firms with low profitability. The $R M W$ factor embeds this relationship.

Fama and French show that, at least at the theoretical level, the $C M A$ and $R M W$ factors substitute to the HML factor. To do so, they rewrite the seminal Miller and Modigliani (1961) equation in terms of the book-to-market ratio:

$$
\frac{1}{\text { book-to-market }}=\frac{\sum_{\tau=1}^{\infty} E\left(Y_{t+\tau}-d B_{t+\tau}\right) /(1+r)^{\tau}}{B_{t}}
$$

where $Y_{t+\tau}$ is earnings for period $t+\tau ; B_{t}$ is the equity book value; $d B_{t}$ is the change in $B_{t}{ }^{7}$ and $r$ is the expected stock return. According to equation (4), a higher book-to-market ratio implies a higher $r$. Moreover, a higher book-to-market entails a lower profitability $\left(Y_{t+\tau}\right)$, all else equal. Finally, a higher book-to-market ratio is related to a lower level of investment. Therefore, $C M A$ and $R M W$ substitute to $H M L$.

\section{Empirical results}

3.1 Data

The hedge fund strategies' returns are taken from the database managed by Greenwich Alternative Investment (GAI). GAI manages one of the oldest hedge fund databases, containing more than 13,500 records of hedge funds as of March 2010. Returns provided by the database are net of fees. The survivorship bias is accounted for in this database, as index returns for periods since 1994 include the defunct funds. The dataset runs from January 1995 to September 2012, for a total of 213 observations. In addition to the weighted composite return, the database includes 9 return series of well-known hedge fund strategies. Finally, the Fama and French

${ }^{7}$ Note that investment represents a decrease in the book value of equity $\left(B_{\mathrm{t}}\right)$-i.e., an expense or a negative cash-flow. Instead of putting $d B$ in equation (4), Miller and Modigliani (1961) put $I$ in their original equation-i.e., equation (9) in their 1961 article. 
factors are drawn from French's database ${ }^{8}$ and the Fung and Hsieh lookback straddles come from Hsieh's database ${ }^{9}$.

Insert Figure 1 here

\subsection{Stylized facts}

Figure 1 provides the cross-correlations of the $C M A$, RMW and $H M L$ with the market return $(m k t)$ and between themselves. The correlation of $C M A$ and $R M W$ with $m k t$ is negative and high in absolute value at time $t$, and $R M W$ is even correlated negatively with mkt at time $t+1$. $H M L$ is also negatively related to the $m k t$ a time $\mathrm{t}$ but the correlation is positive and significant at time $t-1$. These factors thus tend to have a higher expected return when the market trends downward and vice versa when the market trends upward.

At time $t$, the correlation of $C M A$ with $H M L$, at 0.65 , is higher than the correlation between $R M W$ and $H M L$, i.e., 0.52 , but the correlation between $R M W$ and $H M L$ is much more persistent. This indicates that $R M W$ and $H M L$ share common cycles. Overall, cross correlations show that the interactions between $R M W$ and $C M A$, on the one hand, and $H M L$, on the other hand, are high.

\section{Insert Figure 2 here}

A look at the plot of orthonormal loadings of the Fama and French factors computed with the principal components analysis might help to see the links between them. According to Figure 2, CMA and HML are very close factors, which does not seem the case for $R M W$. Not surprisingly, $S M B$ is close to the market factor.

\section{Insert Figure 3 here}

Figure 3, which plots the spectra of the factors, gives a different picture. Spectral analysis is used to compare the dynamic aspects or cycles of the factors' time series. We have indicated the length of the cycles on the plots. The business cycle frequency corresponds to the shaded areas-i.e., it is contained in the interval ranging from 18 months (six quarters) to 120 months (40 quarters) (DeJong and Dave, 2007). The spectra which are the most similar are those of $H M L$ and $R M W$. Both have a peak in the zone of the business cycle frequency and another at a cycle lasting 3.5 months. Similarly to the market factor, the spectrum of $C M A$ is more akin to the one of a random variable.

Insert Table 1 here

We can get a better grasp of the links between the factors by running Granger causality tests (Table 1). The Granger test between $C M A$ and $H M L$ is significant in both directions: $H M L$ Granger causes $C M A$, and CMA Granger causes $H M L$, the latter test being more significant than the former. In other respects, $R M W$ Granger causes $H M L$, this test being more significant than for $C M A$. However, $H M L$ does not Granger causes $R M W$. Surprizingly, $S M B$ Granger causes $C M A$ and $R M W$, suggesting that the link between $S M B$ and the two new factors is quite close. Size does impact investment and profitability.

Summarizing, it is difficult to assess a priori which of $C M A$ or $R M W$ is closest to $H M L$. That depends on the framework we adopt. In a static framework, $C M A$ seems closer to $H M L$ while in a dynamic one, $R M W$ is closer. But regardless of the perspective, the links between

${ }^{8}$ The address of French's website is: http://mba.tuck.dartmouth.edu/pages/faculty/ken.french/data_library.html.

${ }^{9}$ The address of Hsieh database is: https://faculty.fuqua.duke.edu/ dah7/HFData.htm. 
these three factors are strong even if we can discard that $C M A$ and $R M W$ are perfect substitutes to $H M L$. Consequently, the redundancy of $H M L$ is not established by the stylized facts.

\subsection{Testing the redundancy of $H M L$}

To further investigate the issue related to the redundancy of $H M L$, we first estimate the Fama and French (1993) three-factor model with our sample of hedge fund strategies to measure the relative importance of this factor:

$$
R_{i t}-r_{f t}=\alpha+\beta_{1}\left[R_{m t}-r_{f t}\right]+\beta_{2} S M B_{t}+\beta_{3} H M L_{t}+\beta_{4} \operatorname{ar}(1)+\varepsilon_{t}
$$

We then estimate the five-factor model (equation (3)) with and without $H M L$ to see how the weight of $H M L$ is redistributed between $C M A$ and $R M W$.

Before analyzing the results, note that we have included an ar(1) term in our estimation process to account for the autocorrelation of order 1 between returns. If markets are efficient, there should be no autocorrelation between returns because otherwise they become predictable. But in the hedge fund industry, autocorrelation may be due to return smoothing or to infrequent trading giving rise to illiquidity (Okunev and White, 2003; Pástor and Stambaugh, 2003; Getmansky et al., 2004; Chan et al., 2007; Brown et al., 2012; Chen and Tindall, 2012). This autocorrelation contributes to hide the effective risk in the hedge fund industry. Moreover, it gives rise to estimation biases if not accounted for. We rely on an $\operatorname{ar}(1)$ term to tackle autocorrelation created by return smoothing or illiquidity in our estimations (Okunev and White, 2003; Bali et al., 2014) ${ }^{10}$.

Insert Table 2 here

Table 2 provides the estimation of equation (5) for the hedge funds' general index and for strategies. Note first that the explanatory power of the three-factor model is good for the general index and for many strategies-i.e., long-short, growth, short-sellers and value indexthe adjusted $R^{2}$ exceeding 0.75 in these cases. However for other strategies-futures, macro and equity market neutral - this model has a very low explanatory power. The adjusted $R^{2}$ seems colinear to the market beta: the higher the beta of a strategy, the higher its $R^{2}$.

Most strategies display a significant $\operatorname{ar}(1)$ coefficient, which suggests illiquidity and return smoothing in the hedge fund industry. The coefficient of autocorrelation is also nonnegligible for these strategies, ranging from 0.14 for the market neutral strategy to 0.31 for the distressed securities strategy. Three strategies do not show any evidence of autocorrelation: macro, short-sellers and futures.

As expected, the beta is generally low in the hedge fund industry, and usually much lower than the market portfolio beta which is equal to one by definition. Over the whole sample period, it is equal to 0.29 for the general index with a maximum of 0.59 for the growth strategy. Note that short-sellers which are involved in a contrarian strategy with respect to the market display a negative beta (-0.80) which is quite important in absolute value. Some strategies have a beta close to 0 , like futures (-0.06) and equity market neutral (0.07).

The second factor in importance which impacts hedge fund returns is $S M B$, its estimated coefficient being 0.23 for the general index. Except for short sellers, hedge funds

${ }^{10}$ Note that there are more sophisticated ways to account for return smoothing. See Getmansky et al. (2004) and Brown et al. (2012).

Telfer School of Management, WP.2015.04 
generally prefer a positive exposure to the stocks of small firms over the stocks of big firms. Strategies with a higher beta usually display a higher exposure to $S M B$. The negative exposure of short sellers to $S M B$, at -0.54, is once more quite high.

The factor which interests us in this study, $H M L$, is also usually a significant factor for hedge fund strategies, albeit less important than $S M B$. Hedge funds usually short $H M L$. They thus tend to prefer growth stocks over value stocks. For instance, the negative exposure of the general index to $H M L$ is equal to -0.12. Once more, the relative exposure of hedge fund strategies to $H M L$ is in ascending order of their exposures to the market return and $S M B$. In this respect, the exposures of the growth and opportunistic strategies are equal to -0.37 and 0.23, respectively. Since short-sellers follow a contrarian strategy compared to the other ones ${ }^{11}$, its exposure to $H M L$, at 0.50 , is positive and high in absolute value. It is in line with its substantial negative exposure to the market and to $S M B$.

Insert Table 3 here

Table 3 provides the estimation of the complete Fama and French five-factor model (equation (3)) and the estimation of the corresponding four-factor model excluding HML. These estimations aim at testing, on the one hand, whether the impact of $H M L$ becomes redundant when including the two new factors $C M A$ and $R M W$, and, on the other hand, at analyzing how the weight of $H M L$ is redistributed between $C M A$ and $R M W$ when omitting it from the fivefactor equation. Fama and French (2015) found that $H M L$ has a tendency to become redundant when including $C M A$ and $R M W$ in their original three-factor model. They also suggest that the exposure to $H M L$ in their three-factor model will be mostly captured by $C M A$ than $R M W$. We now investigate if these results hold in the framework of our sample.

First, we observe that $H M L$ becomes usually redundant when introducing $C M A$ and $R M W$ in the factor model. It is the case for the general index and the following strategies: longshort, macro, value index, event driven strategies ${ }^{12}$. Note that the weight of $H M L$ in the threefactor model is shared between $C M A$ and $R M W$ and not exclusively by $C M A$. Moreover, the sum of the exposures to $C M A$ and $R M W$ is higher, in absolute value, than the exposure of hedge fund strategies' returns to $H M L$ in the three-factor model. However, for four strategies-i.e., growth, short-sellers, equity market neutral and opportunistic index- $H M L$ remains significant when shifting from the three-factor to the five-factor model. Excepting the equity market neutral strategy, the exposure of these strategies to $H M L$ is relatively high in the three-factor model. For instance, the exposure of the growth strategy to $H M L$ is equal to -0.37 in the threefactor model. It decreases (in absolute value) to -0.19 in the five-factor model, and the exposures to $C M A$ and $R M W$ are equal to -0.20 and -0.28 , respectively. For one strategy-i.e., the short sellers - the exposure to $H M L$ does not decrease when adding $C M A$ and $R M W$ to the set of factors. It remains at 0.50, significant at the 5\% level, and the $C M A$ and $R M W$ factors are not significant. When dropping $H M L$, the coefficients of $C M A$ and $R M W$ are equal to 0.62 and 0.36 , respectively, both significant at the $5 \%$ level, suggesting again that $H M L$ may embed the impacts of $C M A$ and $R M W$ consistent with the Granger causality tests.

Except for short sellers which adopt a contrarian strategy, the exposures to $C M A$ and $R M W$ is negative for the hedge fund strategies. Therefore, hedge funds tend to prefer, on the one hand, firms which invest a lot to firms which invest less, and, on the other hand, weak firms to robust ones. These exposures parallel the hedge fund strategies' exposure to $H M L$ which is

${ }^{11}$ Excepting the futures strategy.

${ }^{12}$ Note that we list only the strategies which have a significant exposure to $H M L$ in the Fama and French three-factor model. 
negative in our sample. However, as mentioned previously, $H M L$ firms tend to have a low investment ratio and tend to be less profitable. Thus, the positive link between $C M A$ and $H M L$ is more obvious than the positive link between $R M W$ and HML. RMW may embed risk dimensions which are not included in HML. For instance, the distressed strategy is neither sensitive to $H M L$ nor $C M A$ but reacts negatively and significantly to $R M W$. Indeed, the distressed strategy is oriented toward the investment in stocks of weak firms which have a potential to recover.

In other respects, the five-factor model does not mitigate the hedge fund alpha puzzle. Shifting from the three to the five-factor model does not decrease the strategies' alpha: it even increases for many of them. In this sense, for hedge funds, the five-factor model is not a "more complete" model than the three-factor model.

Summarizing, consistent with the Fama and French's conjecture, our results show that for the majority of the strategies, the $C M A$ and $R M W$ factors substitute to $H M L$. However, this is not always the case. When the HML coefficient is high and significant in the three-factor model, it tends to remain significant in the five-factor model even if the two factors associated with the $q$-factor model are also significant. When removing the $H M L$ factor in this situation, the exposures to $C M A$ and $R M W$ factors increases significantly in absolute value, which confirms the strong interaction between the three factors. Overall, consistent with the stylized facts, HML seems to embed information not contained in the other factors even if they are strongly interactive. In this respect, we cannot assess that $C M A$ captures most of the weight of $H M L$ in the four-factor model-i.e., which excludes $H M L$ - since $R M W$ usually absorbs a nonnegligible portion of the weight of $H M L$.

\subsection{Robustness check: An augmented version of the five-factor model encompassing the Fung and Hshieh empirical model}

As a robustness check, we augment Fama and French's five factor model with the seven factors proposed by Fung and Hsieh $(1997,2001,2004)$ to account for the dynamic dimensions of hedge fund strategies. These factors comprise five categories of straddle lookbacks, the change in the ten-year interest rate, and a change in the credit spread. The lookback straddleswhich are especially useful to study the trend followers-are: the bond lookback, the stock lookback, the short-interest lookback, the currency lookback and the commodity lookback. Following the addition of these seven factors, our return model takes the following form:

$$
\begin{aligned}
& R_{i t}-r_{f t}=\alpha+\beta_{1}\left(R_{m t}-r_{f t}\right)+\beta_{2}(S M B)_{t}+\beta_{3} C M A+\beta_{4} R M W+\beta_{5} \text { bond }_{-} \text {look }_{t}+\beta_{6} \text { stock } \text { look }_{t}+\ldots \\
& +\beta_{7} \text { shortint_look } k_{t}+\beta_{8} \text { currency_look }_{t}+\beta_{9} \text { commod_look }_{t}+\beta_{10} d\left(\text { CredSpr }_{t}\right)+\beta_{11} d\left(10 Y_{t}\right)+\beta_{12} \text { ar }(1)+\varepsilon_{t}
\end{aligned}
$$

where $d(C r e d S p r)$ stands for the change in the credit spread-i.e., the spread between the BBB and AAA U.S. corporate bond yields; $d\left(10 \Upsilon_{t}\right)$ in the change in the rate of the 10-year U.S. federal government bond.

Insert Table 4 here

Table 4 provides the estimation of equation (6) for the hedge fund general index and strategies. While there was no obvious change in the adjusted $R^{2}$ when shifting from the three 
to four-factor model ${ }^{13}$, introducing the seven Fung and Hsieh factors in the estimation leads to increases in the adjusted $\mathrm{R}^{2}$ which may be substantial for some strategies. For instance, while the four-factor model has no explanatory power for the futures strategy, the adjusted $R^{2}$ associated with the eleven-factor model is equal to 0.34 for this strategy. Option-like trading strategies thus play a great role for futures, all lookbacks being significant in its equation. The adjusted $R^{2}$ of the macro strategy also jumps from 0.15 to 0.30 when using the eleven-factor model rather than the four-factor one.

Adding the seven Fung and Hsieh factors has only a marginal impact on the estimation of the coefficients associated with the Fama and French four-factor model. The lookbacks impacting the most hedge fund strategies' returns are the short-interest, stock and currency lookbacks. The short-interest lookback affects significantly all strategies except short-sellers. The strategies have a negative exposure to this kind of lookback. Note that, with a correlation close to 0.70 , the short interest lookback is the most related to the first principal component of the five Fung and Hsieh's lookbacks. This component has a negative beta (-0.10) and thus helps immunize against market risk. Our results thus suggest that the short-interest rate lookback plays a major role in the hedging operations of hedge funds. The general index and many directional strategies-i.e., long-short, macro and growth-have a positive and significant exposure to the stock lookback. Moreover, as expected, strategies more involved in arbitragei.e., distressed, event-driven and equity market neutral-display a negative and significant exposure to the bond lookback. In addition to the general index, many strategies-i.e., longshort, value index, distressed securities and event-driven-have a negative and significant exposure to the change in the credit spread.

Finally, the addition of the Fung and Hsieh's seven factors to the Fama and French's four-factor model does not help solve the hedge fund alpha puzzle. It even exacerbates it in many cases, the alpha being greater for many strategies. It seems that other factors must be considered to mitigate the puzzle.

\section{Conclusion}

To the best of our knowledge, this study is the first to transpose the $q$-factor model to hedge fund strategies. The advantage of this model is that it relies on a robust theoretical framework. We showed that it proves useful to better describe the hedge fund strategies. The new factors $C M A$ and $R M W$ are very significant for a majority of strategies. In our sample, hedge funds seem to prefer weak firms to robust ones, but also firms with a high investment ratio to firms with a low one. This selection is akin to the puzzle discovered by Fama and French (2015) in their experiments.

In contrast to Fama and French (2015) which seem to assess that HML is redundant when adding $C M A$ and $R M W$, we cannot be so categorical regarding our sample of hedge funds' strategies. Consistent with Fama and French's (2015) conjecture, HML becomes redundant for many strategies when adding the two new factors. However, for some of them-especially when

${ }^{13}$ i.e., the model including the market risk premium, $S M B, C M A$ and $R M W$. 
$H M L$ weights heavily in the three-factor model- $H M L$ coexists with $C M A$ and $R M W$. $H M L$ thus seems to embed risk dimensions which are not included in the Fama and French new factors.

In contrast to the study of Fama and French (2015) where the alpha tends to zero in their five-factor model, the addition of $C M A$ and $R M W$ does not solve the hedge fund alpha puzzle: alpha is robust to the inclusion of these factors. We also find that the Fung and Hsieh (1994, 2001, 2004) factors-which account for the option-like trading strategies followed by hedge funds - add more explanatory power to the hedge fund return model than the two new Fama and French factors ${ }^{14}$. But once more, the Fung and Hsieh factors do not solve the hedge fund alpha puzzle. They even exacerbate it.

${ }^{14}$ When excluding $H M L$. 


\section{References}

Bali, T.G., Brown, S.J., Caglayan, M.O., 2014. Macroeconomic risk and hedge fund returns. Journal of Financial Economics 114, 1-19.

Brown, S.J., Gregoriou, G., Pascalau, R., 2012. It is possible to overdiversify? The case of funds of hedge funds. Review of Asset Pricing Studies 2, 89-110.

Carhart, M., 1997. On persistence in mutual fund performance. Journal of Finance 52, 57-82.

Chan, N., Getmansky, M., Haas, S.M., Lo, A.W., 2007. Systemic risk and hedge funds. Working Paper, NBER.

Cochrane, J., 1991. Production-based asset pricing and the link between stock returns and economic fluctuations. Journal of Finance 46, 209-237.

DeJong, D.N., Dave, C., 2007. Structural macroeconometrics. Princeton University press. Princeton.

Fama, E.F., French, K.R., 1993. Common risk factors and the returns on stocks and bonds. Journal of Financial Economics 33, 3-56.

Fama, E.F., French, K.R., 2015. A five-factor asset pricing model. Journal of Financial Economics 116, 122. .

Fazzari, S., Hubbard, R.G., Petersen, B., 1988. Financing constraints and corporate investment. Brookings Papers on Economic Activity, 141-195.

Fisher, I., 1930. The Theory of Interest: As Determined by Impatience to Spend Income and Opportunity to Invest it. New York: Macmillan.

Fung, W., Hsieh, D.A., 1997. Empirical characteristics of dynamic trading strategies: The case of hedge funds. Review of financial studies 10, 275-302.

Fung, W., Hsieh, D.A., 2001. The risk in hedge fund strategies: Theory and evidence from trend followers. Review of Financial Studies 14, 313-341.

Fung, W., Hsieh, D.A., 2004. Hedge fund benchmarks: A risk based approach. Financial Analysts Journal 60, 65-80.

Getmansky, M., Lo, A.W., Makarov, I., 2004. An econometric model of serial correlation and illiquidity in hedge fund returns. Journal of Financial Economics 74, 529-609.

Hou, K., Xue, C., Zhang, L. 2014. Digesting anomalies : An investment approach. Review of Financial Studies, forthcoming.

Miller, M., Modigliani, F., 1961. Dividend policy, growth, and the valuation of shares. Journal of Business 34, 411-433.

Okunev, J., White, D., 2003. Hedge fund risk factors and value at risk of credit trading strategies. Working Paper. University of New South Wales.

Pástor, L., Stambaugh, R., 2003. Liquidity risk and expected stock returns. Journal of Political Economy $111,642-685$.

Thomas, J.P., Worrall, T., 2014. Dynamic relational contracts under complete information. Working Paper, University of Edinburgh.

Tobin, J., 1969. A general equilibrium approach to monetary theory. Journal of Money, Credit and Banking 1, 15-29. 


\section{Tables}

Table 1 Granger causality tests

\begin{tabular}{llc}
\hline \multicolumn{1}{c}{ Test } & \multicolumn{2}{c}{ Statistics } \\
\hline \multirow{2}{*}{ HML Granger causes (GC) CMA } & F-statistic & 1.72 \\
& p-value & $0.06^{*}$ \\
CMA GC HML & F-statistic & 1.93 \\
& p-value & $0.03^{* *}$ \\
HML GC RMW & F-statistic & 1.21 \\
& p-value & 0.27 \\
RMW GC HML & F-statistic & 2.27 \\
& p-value & $0.01^{* *}$ \\
SMB GC CMA & F-statistic & 2.51 \\
& p-value & $0.01^{* *}$ \\
CMA GC SMB & F-statistic & 0.78 \\
& p-value & 0.66 \\
SMB GC RMW & F-statistic & 3.09 \\
& p-value & $0.01^{* *}$ \\
RMW GC SMB & F-statistic & 1.46 \\
& p-value & 0.14 \\
\hline
\end{tabular}

Notes: When the test accepts the hypothesis of causality, its $p$-value has one * if the test is significant at the $10 \%$ level and ** if the test is significant at the $5 \%$ level. 
Table 2 The Fama and French three-factor model

\begin{tabular}{|c|c|c|c|c|c|c|}
\hline & c & mkt_rf & SMB & HML & $\operatorname{ar}(1)$ & $\mathbf{R}^{2} / \mathbf{D W}$ \\
\hline \multirow[t]{2}{*}{ gi } & 0.004 & 0.29 & 0.23 & -0.12 & 0.22 & 0.76 \\
\hline & 4.88 & 18.08 & 11.20 & -5.66 & 3.15 & 2.00 \\
\hline \multirow[t]{2}{*}{ Is } & 0.004 & 0.43 & 0.34 & -0.15 & 0.30 & 0.82 \\
\hline & 3.14 & 22.33 & 13.73 & -5.75 & 4.59 & 2.04 \\
\hline \multirow[t]{2}{*}{ macro } & 0.002 & 0.18 & 0.17 & -0.15 & 0.02 & 0.15 \\
\hline & 0.88 & 4.12 & 2.82 & -2.52 & 0.34 & 1.98 \\
\hline \multirow[t]{2}{*}{ gr } & 0.003 & 0.59 & 0.47 & -0.37 & 0.18 & 0.80 \\
\hline & 1.96 & 20.02 & 12.26 & -8.98 & 2.65 & 2.05 \\
\hline \multirow[t]{2}{*}{ ss } & 0.001 & -0.80 & -0.54 & 0.50 & -0.01 & 0.78 \\
\hline & 0.51 & -19.4 & -9.74 & 10.61 & -0.09 & 2.00 \\
\hline \multirow[t]{2}{*}{ fut } & 0.006 & -0.06 & -0.03 & 0.10 & 0.02 & 0.00 \\
\hline & 2.65 & -1.09 & -0.04 & 1.35 & 0.32 & 1.95 \\
\hline \multirow[t]{2}{*}{ vi } & 0.005 & 0.47 & 0.33 & -0.11 & 0.27 & 0.82 \\
\hline & 4.06 & 24.31 & 13.12 & -4.36 & 3.98 & 1.99 \\
\hline \multirow[t]{2}{*}{ ds } & 0.005 & 0.16 & 0.17 & -0.03 & 0.31 & 0.44 \\
\hline & 3.59 & 7.61 & 6.44 & -1.23 & 4.71 & 2.04 \\
\hline \multirow[t]{2}{*}{ ed } & 0.005 & 0.23 & 0.26 & -0.05 & 0.25 & 0.66 \\
\hline & 4.50 & 13.27 & 11.21 & -1.98 & 3.72 & 2.04 \\
\hline \multirow[t]{2}{*}{ emn } & 0.004 & 0.07 & 0.13 & -0.03 & 0.14 & 0.22 \\
\hline & 4.81 & 3.61 & 5.56 & -1.57 & 2.01 & 2.03 \\
\hline \multirow[t]{2}{*}{ oi } & 0.005 & 0.35 & 0.37 & -0.23 & 0.21 & 0.67 \\
\hline & 3.38 & 12.77 & 10.33 & -5.95 & 3.14 & 2.06 \\
\hline
\end{tabular}

Notes: gi is the return on the GAI general index. The list of the selected strategies is: ls (long-short); macro; gr (growth); ss (shortsellers); fut (futures); vi (value index); ds (distressed securities); ed (event driven); emn (equity market neutral); oi: opportunistic index. The $t$ statistics are in italics. $m k t \_r f$ is the market risk premium. $\operatorname{ar}(1)$ is an autoregressive factor of order 1. 
Table 3 The Fama and French four-factor and five-factor model

\begin{tabular}{|c|c|c|c|c|c|c|c|c|}
\hline & c & mkt_rf & SMB & HML & CMA & RMW & $\operatorname{ar}(1)$ & $\mathbf{R}^{2} / \mathbf{D W}$ \\
\hline \multirow[t]{4}{*}{ gi } & 0.005 & 0.26 & 0.19 & \begin{tabular}{|c|}
-0.03 \\
\end{tabular} & \begin{tabular}{|c|}
-0.11 \\
\end{tabular} & \begin{tabular}{|c|}
-0.13 \\
\end{tabular} & 0.24 & 0.71 \\
\hline & 5.67 & 14.35 & 7.98 & -1.15 & -2.43 & -3.45 & 3.60 & 1.97 \\
\hline & 0.005 & 0.25 & 0.19 & & -0.14 & -0.15 & 0.25 & 0.77 \\
\hline & 5.84 & 14.53 & 7.89 & & -4.38 & -4.78 & 3.74 & 1.97 \\
\hline \multirow[t]{4}{*}{ Is } & 0.005 & 0.38 & 0.28 & -0.02 & -0.17 & -0.17 & 0.34 & 0.83 \\
\hline & 4.11 & 18.22 & 10.09 & -0.57 & -3.36 & -4.02 & 5.21 & 2.01 \\
\hline & 0.005 & 0.37 & 0.28 & & -0.20 & -0.19 & 0.35 & 0.83 \\
\hline & 4.20 & 18.69 & 10.16 & & -5.13 & -5.12 & 5.30 & 2.01 \\
\hline \multirow[t]{4}{*}{ macro } & 0.003 & 0.11 & 0.12 & 0.05 & -0.34 & -0.18 & 0.04 & 0.18 \\
\hline & 1.72 & 2.27 & 1.78 & 0.56 & -2.67 & -1.78 & 0.62 & 1.98 \\
\hline & 0.003 & 0.12 & 0.12 & & -0.29 & -0.15 & 0.04 & 0.18 \\
\hline & 1.65 & 2.49 & 1.84 & & -3.08 & -1.96 & 0.54 & 1.98 \\
\hline \multirow[t]{4}{*}{ gr } & 0.005 & 0.52 & 0.38 & -0.19 & -0.20 & -0.28 & 0.18 & 0.82 \\
\hline & 3.22 & 16.07 & 8.69 & -3.18 & -2.43 & -4.18 & 2.57 & 2.02 \\
\hline & 0.006 & 0.50 & 0.38 & & -0.38 & -0.39 & 0.20 & 0.81 \\
\hline & 3.59 & 15.46 & 8.31 & & -6.08 & -6.71 & 2.96 & 2.02 \\
\hline \multirow[t]{4}{*}{ ss } & 0.000 & -0.77 & -0.53 & 0.51 & 0.15 & 0.06 & -0.01 & 0.78 \\
\hline & 0.09 & -16.10 & -8.12 & 5.80 & 1.23 & 0.70 & 0.81 & 2.00 \\
\hline & -0.002 & -0.69 & -0.49 & & 0.62 & 0.36 & 0.01 & 0.75 \\
\hline & -0.95 & -13.92 & -7.03 & & 6.43 & 4.11 & 0.11 & 1.99 \\
\hline \multirow[t]{4}{*}{ fut } & 0.006 & -0.03 & -0.01 & 0.02 & 0.16 & 0.01 & 0.02 & 0.00 \\
\hline & 2.30 & -0.61 & -0.15 & 0.23 & 1.06 & 0.06 & 0.23 & 1.96 \\
\hline & 0.006 & -0.03 & -0.01 & & 0.19 & 0.02 & 0.01 & 0.00 \\
\hline & 2.31 & -0.57 & -0.13 & & 1.65 & 0.22 & 0.82 & 1.96 \\
\hline \multirow[t]{4}{*}{ vi } & 0.006 & 0.43 & 0.30 & 0.01 & -0.23 & -0.11 & 0.34 & 0.84 \\
\hline & 4.70 & 20.20 & 10.45 & 0.34 & -4.28 & -2.55 & 5.04 & 1.98 \\
\hline & 0.006 & 0.43 & 0.30 & & -0.22 & -0.11 & 0.33 & 0.84 \\
\hline & 4.72 & 20.98 & 10.53 & & -5.50 & -2.81 & 5.01 & 1.94 \\
\hline \multirow[t]{4}{*}{ ds } & 0.006 & 0.13 & 0.14 & 0.03 & -0.07 & -0.12 & 0.31 & 0.45 \\
\hline & 4.13 & 5.65 & 4.20 & 0.72 & -1.17 & -2.36 & 4.49 & 2.04 \\
\hline & 0.006 & 0.14 & 0.14 & & -0.04 & -0.10 & 0.32 & 0.45 \\
\hline & 4.01 & 5.99 & 4.24 & & -0.97 & -2.34 & 4.76 & 2.05 \\
\hline \multirow[t]{4}{*}{ ed } & 0.005 & 0.22 & 0.21 & -0.01 & 0.00 & -0.12 & 0.24 & 0.67 \\
\hline & 5.07 & 10.87 & 7.80 & -0.19 & -0.02 & -3.02 & 3.55 & 2.03 \\
\hline & 0.006 & 0.22 & 0.21 & & -0.01 & -0.13 & 0.24 & 0.67 \\
\hline & 5.17 & 11.22 & 7.83 & & -0.21 & -3.68 & 3.54 & 2.03 \\
\hline \multirow[t]{4}{*}{ emn } & 0.004 & 0.07 & 0.11 & -0.06 & 0.08 & -0.04 & 0.12 & 0.23 \\
\hline & 4.64 & 3.32 & 3.94 & -1.62 & 1.69 & -0.98 & 1.78 & 2.02 \\
\hline & 0.005 & 0.06 & 0.11 & & 0.03 & -0.08 & 0.13 & 0.24 \\
\hline & 4.91 & 2.98 & 3.79 & & 0.78 & -2.17 & 1.94 & 2.03 \\
\hline \multirow[t]{4}{*}{ oi } & 0.007 & 0.30 & 0.30 & -0.10 & -0.12 & -0.22 & 0.22 & 0.69 \\
\hline & 4.23 & 9.80 & 7.12 & -1.79 & -1.58 & -3.48 & 3.26 & 2.04 \\
\hline & 0.007 & 0.29 & 0.29 & & -0.22 & -0.28 & 0.24 & 0.68 \\
\hline & 4.44 & 9.61 & 6.96 & & -3.81 & -5.18 & 3.52 & 2.04 \\
\hline
\end{tabular}

Notes. For each strategy, we test the five-factor model including $H M L$ (first two rows) and the four-factor model excluding $H M L$ (last two rows). The t-statistics are in italics. See Table 2 for the list of the return variables.

Table 4 The Fama and French four-factor model augmented with the seven Fung and Hsieh factors 


\begin{tabular}{|c|c|c|c|c|c|c|c|c|c|c|c|}
\hline & GI & LS & MACRO & GR & SS & FUT & VI & DS & ED & EMN & OI \\
\hline \multirow[t]{2}{*}{$\overline{\mathrm{C}}$} & 0.007 & 0.007 & 0.007 & 0.008 & -0.002 & 0.008 & 0.007 & 0.006 & 0.006 & 0.005 & 0.009 \\
\hline & 6.86 & 5.24 & 2.89 & 4.38 & -0.87 & 3.04 & 5.35 & 5.33 & 6.81 & 4.85 & 4.78 \\
\hline \multirow[t]{2}{*}{ MKT_RF } & 0.25 & 0.37 & 0.17 & 0.49 & -0.70 & 0.08 & 0.42 & 0.12 & 0.20 & 0.04 & 0.28 \\
\hline & 14.61 & 18.27 & 3.34 & 14.49 & -12.89 & 1.42 & 20.3 & 5.05 & 10.26 & 2.05 & 8.89 \\
\hline \multirow[t]{2}{*}{ SMB } & 0.19 & 0.28 & 0.15 & 0.37 & -0.48 & 0.05 & 0.30 & 0.15 & 0.21 & 0.09 & 0.28 \\
\hline & 8.09 & 10.13 & 2.17 & 8.02 & -6.72 & 0.67 & 10.53 & 4.69 & 8.00 & 3.27 & 6.69 \\
\hline \multirow[t]{2}{*}{ CMA } & -0.18 & -0.23 & -0.32 & -0.41 & 0.65 & 0.22 & -0.25 & -0.07 & -0.04 & 0.00 & -0.27 \\
\hline & -5.63 & -6.11 & -3.36 & -6.57 & 6.55 & 2.22 & -6.41 & -1.52 & -1.07 & 0.04 & -4.62 \\
\hline \multirow[t]{2}{*}{ RMW } & -0.15 & -0.19 & -0.12 & -0.40 & 0.40 & 0.06 & -0.11 & -0.07 & -0.12 & -0.08 & -0.29 \\
\hline & -5.08 & -5.35 & -1.39 & -6.89 & 4.48 & 0.67 & -2.97 & -1.84 & -3.70 & -2.34 & -5.24 \\
\hline \multirow[t]{2}{*}{ BOND_LOOKBACK } & -0.003 & -0.006 & 0.024 & -0.010 & 0.023 & 0.046 & 0.001 & -0.020 & -0.017 & -0.015 & -0.016 \\
\hline & -0.66 & -1.14 & 1.72 & -1.08 & 1.53 & 3.05 & 0.1 & -3.10 & -3.14 & -2.56 & -1.84 \\
\hline \multirow[t]{2}{*}{ STOCK_LOOKBACK } & 0.014 & 0.014 & 0.046 & 0.025 & -0.008 & 0.038 & 0.007 & 0.001 & 0.011 & 0.001 & 0.012 \\
\hline & 2.53 & 2.07 & 2.83 & 2.24 & -0.44 & 2.21 & 1.04 & 0.10 & 1.78 & 0.15 & 1.22 \\
\hline \multirow[t]{2}{*}{ SHORTINT_LOOKBACK } & -0.013 & -0.013 & -0.021 & -0.016 & 0.004 & -0.021 & -0.014 & -0.006 & -0.009 & -0.009 & -0.013 \\
\hline & -4.94 & -4.23 & -2.76 & -3.04 & 0.46 & -2.57 & -4.33 & -1.64 & -3.17 & -2.84 & -2.74 \\
\hline \multirow[t]{2}{*}{ CURRENCY_LOOKBACK } & 0.011 & 0.01 & 0.012 & 0.011 & -0.017 & 0.048 & 0.01 & 0.002 & 0.005 & 0.007 & 0.017 \\
\hline & 2.82 & 2.28 & 1.05 & 1.48 & -1.39 & 3.94 & 2.11 & 0.37 & 1.06 & 1.46 & 2.38 \\
\hline \multirow[t]{2}{*}{ COMMOD_LOOKBACK } & 0.008 & 0.004 & 0.031 & 0.005 & 0.012 & 0.074 & -0.003 & 0.000 & 0.002 & 0.009 & 0.010 \\
\hline & 1.66 & 0.76 & 2.07 & 0.48 & 0.74 & 4.6 & -0.46 & 0.02 & 0.41 & 1.49 & 1.13 \\
\hline \multirow[t]{2}{*}{ D(TAUX_10ANS) } & 0.002 & 0.003 & 0.006 & -0.002 & 0.012 & -0.007 & 0.002 & 0.009 & 0.002 & 0.001 & 0.004 \\
\hline & 0.81 & 0.88 & 0.67 & -0.28 & 1.32 & -0.73 & 0.47 & 2.1 & 0.59 & 0.24 & 0.65 \\
\hline \multirow[t]{2}{*}{ D(CREDIT_SPREAD) } & -0.016 & -0.014 & -0.016 & -0.011 & -0.023 & -0.017 & -0.019 & -0.042 & -0.030 & 0.001 & -0.013 \\
\hline & -2.64 & -1.96 & -0.99 & -0.91 & -1.35 & -0.93 & -2.6 & -5.22 & -4.46 & 0.19 & -1.13 \\
\hline R-squared: & 0.82 & 0.86 & 0.3 & 0.83 & 0.76 & 0.34 & 0.86 & 0.59 & 0.75 & 0.31 & 0.72 \\
\hline F-statistic: & 73.18 & 100.52 & 7.01 & 79.83 & 52.57 & 8.39 & 104.02 & 23.26 & 48.11 & 7.30 & 41.49 \\
\hline DW: & 2.01 & 2.06 & 2.01 & 2.04 & 2.00 & 2.00 & 2.01 & 2.04 & 2.02 & 2.04 & 2.05 \\
\hline
\end{tabular}

Notes: See Table 2 for the list of the return variables.

\section{Figures}

Figure 1 Cross-correlations between Fama and French's factors

$C M A$ and $M K T$

$R M W$ and $M K T$

$H M L$ and $M K T$ 


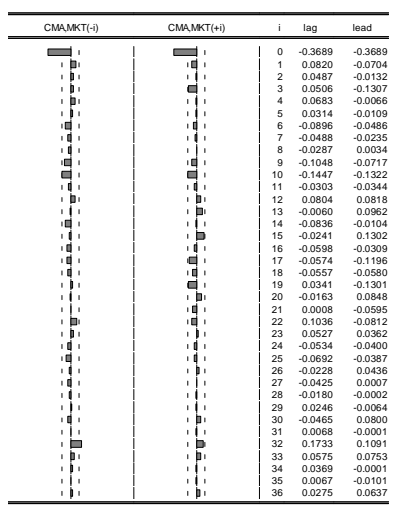

$C M A$ and $H M L$

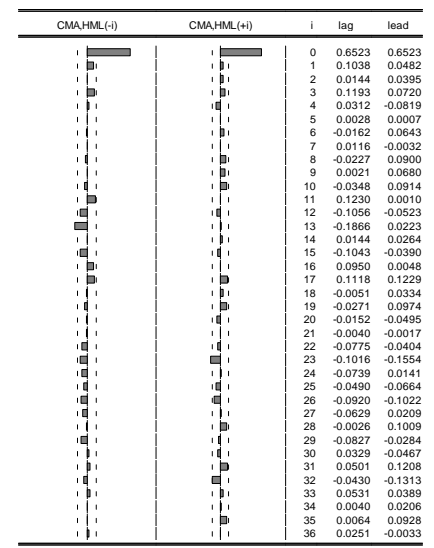

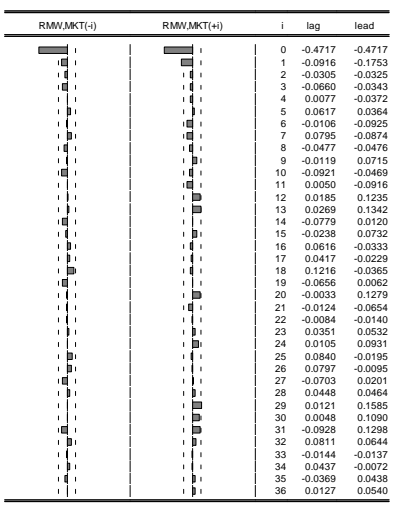

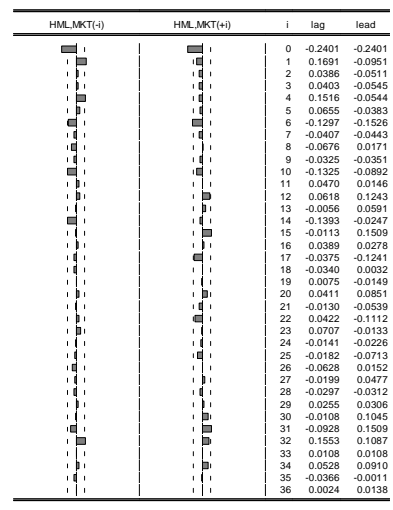

$R M W$ and $H M L$

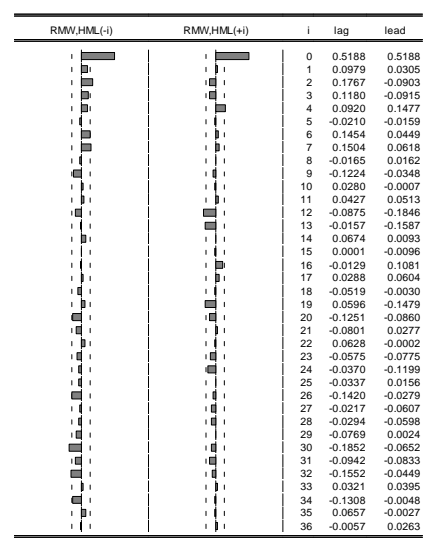

Notes: Each panel provides the correlations of the first factor with the lags and leads of the second factor. The confidence intervals of the correlations appear on the plots. 
Figure 2 Factors' orthonormal loadings

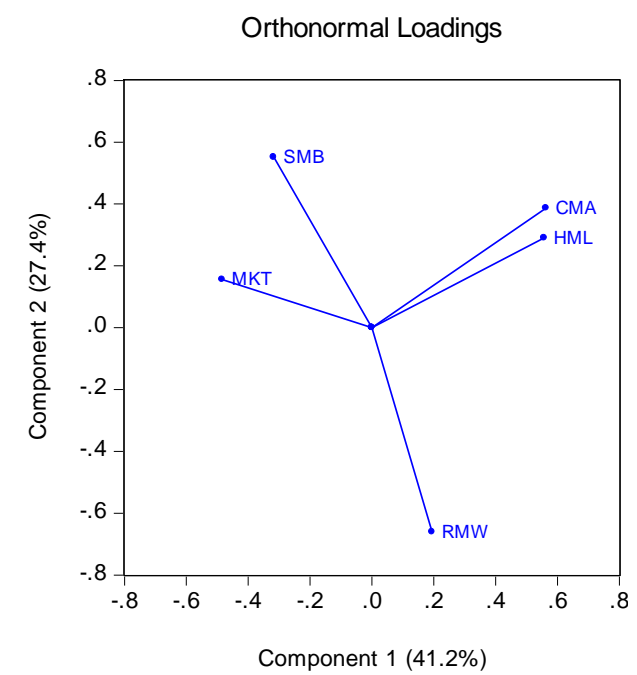

Notes: This plot is built with the two first components resulting from principal components analysis applied to the Fama and French's (2015) five factors. 
Figure 3 Spectra of Fama and French's factors
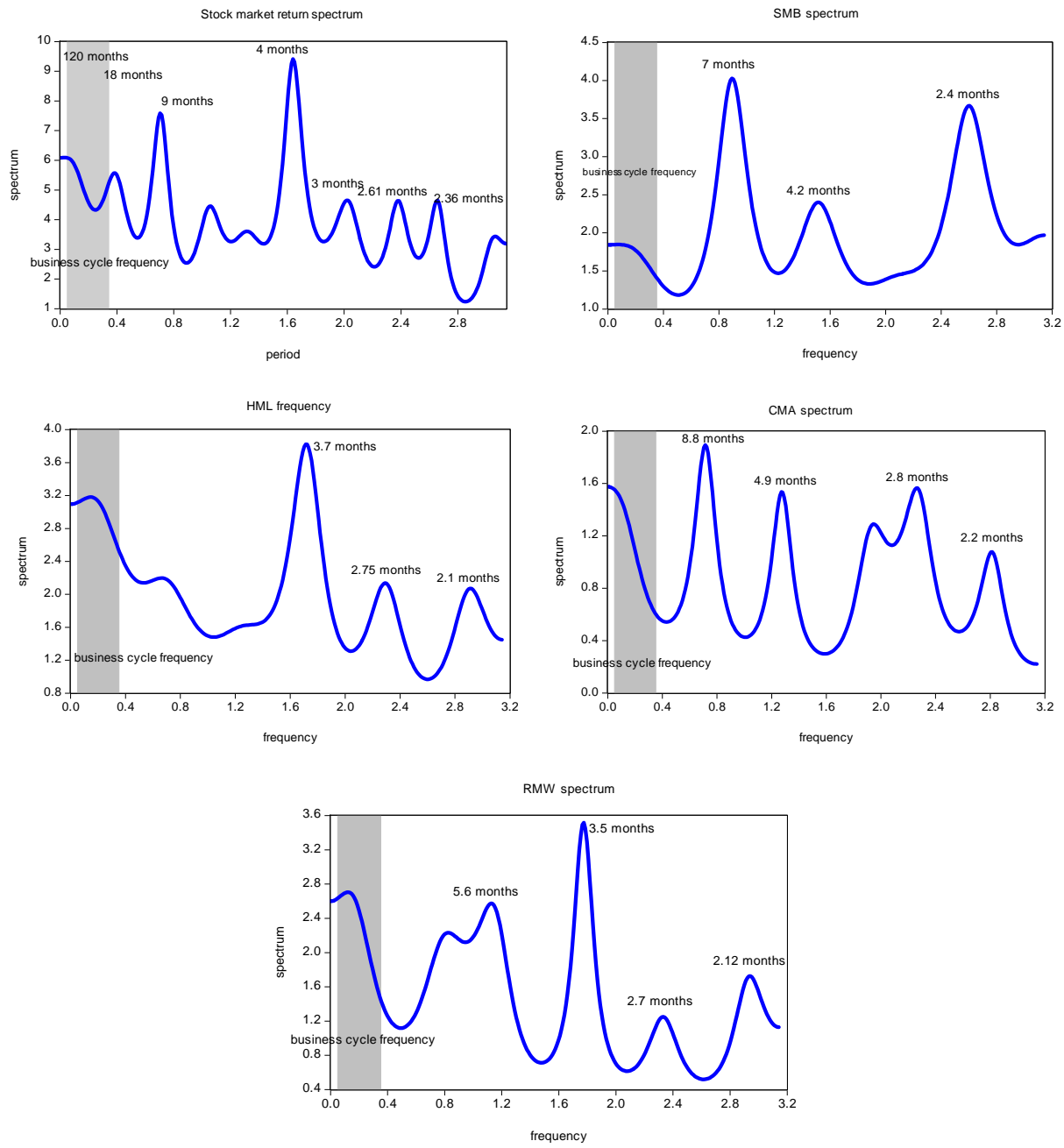

Notes: These spectra are built using an $\operatorname{AR}(p)$ model. Specifically, the spectrum is a decomposition of the variance of a time series by frequency - the cycle frequency being low near the origin add increasing progressively till $\pi$. Comparisons of the height of the spectrum for alternative values of frequency indicate the relative importance of fluctuations at the chosen frequencies in influencing variance in the time series. A spectrum having a peak near the origin indicates that the series is very persistent through time: its autocorrelation function declines very slowly. A spectrum having a peak in the shaded area indicates that this time series has a cycle in the conventional business cycle frequency. A spectrum which shifts to the left through time indicates less volatility for the series, i.e. a more stable series. Shaded areas correspond to the business cycle frequency, which is comprised between 6 and 40 quarters (DeJong and Dave, 2007). 